\title{
The Need for Psychological Interventional Supportive Services for Omani Women Diagnosed with Breast Cancer
}

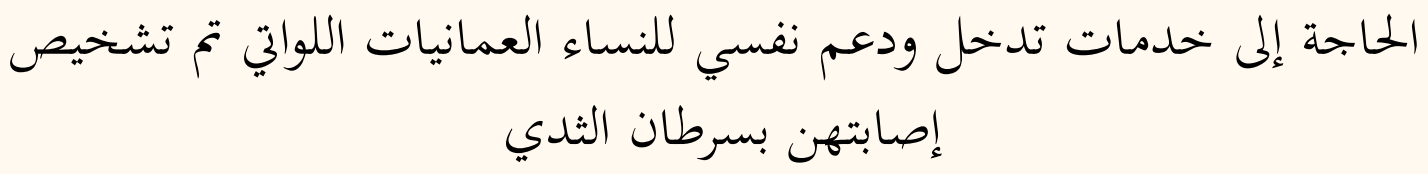

نشأت شمس و محمد العزري

B REAST CANCER IS THE MOST FREQUENTLY diagnosed cancer worldwide (23\%) and the leading cause of cancer-related deaths among women (14\%). ${ }^{1}$ In Oman, the incidence of breast cancer increased from 53 cases in 1996 to 104 cases in 2008, with 100-150 new cases reported annually. ${ }^{2}$ Moreover, in comparison to Western women, women in Oman are often diagnosed in the later stages of cancer, at an earlier age and have lower survival rates., ${ }^{2,3} \mathrm{~A}$ diagnosis of breast cancer can be devastating and can trigger distressing psychological reactions in patients, including feelings of hopelessness, anxiety, fear, loneliness, negative self-image and self-blaming as well as sexual problems. ${ }^{4-6}$ Women with breast cancer have also reported suffering from social discrimination and stigma; hence, they may be less able to cope with the subsequent challenges and adjustments which come with their diagnosis..$^{5-7}$

Psychological interventions are a form of counselling which can minimise the devastating effects and treatment-related symptoms of patients diagnosed with cancer. ${ }^{8,9}$ During direct face-to-face interpersonal sessions, counsellors use various techniques, such as education, coping skills training, psychotherapy and relaxation, either alone or in combination. ${ }^{8,9}$ The aim of these types of therapies is to help the patient resolve any psychological disturbances arising from their cancer diagnosis and teach them the necessary skills to cope, both during and after cancer treatment, so as to enhance their health-related quality of life (QoL). ${ }^{10}$ These interventions can be used for patients of both genders with many different types of cancer. ${ }^{11}$ Research has shown that psychological interventions can give a feeling of empowerment to women who are diagnosed with cancer, thus improving the QoL of breast cancer sufferers and survivors. ${ }^{12,13}$
Psychological and mindful therapies have also been found to positively affect psychological outcomes in women with breast cancer, such as anxiety, depression and mood disturbance; as such, it is recommended that this type of therapy be initiated as soon as a cancer diagnosis is confirmed. ${ }^{14}$ Another type of therapeutic intervention is supportive-expressive group therapy which involves many cancer patients receiving treatment at once, allowing them to analyse and express their concerns more effectively. ${ }^{15}$ This form of therapy provides a platform for patients to express their emotions, improves familial and social relationships and teaches patients to cope with their cancer symptoms. ${ }^{16}$ Qualified counsellors conduct these sessions in person, helping cancer patients to deal with their emotional pain and distress and encouraging them to speak openly about their health conditions. ${ }^{15,16}$

A study of Omani women diagnosed with breast cancer revealed that they encountered psychological and social distress post-diagnosis which affected their personal and social lives. ${ }^{5}$ The women reported being worried about death; feeling that their future was threatened; that their families were shocked by their diagnosis; that the cancer interfered with their work and their familial responsibilities; feeling isolated from society; and reluctance to disclose their diagnosis to other people. ${ }^{5}$ Another study found that Omani women diagnosed with breast cancer used numerous strategies to cope with their symptoms, including denial, social withdrawal, religion and support from family members and healthcare providers. ${ }^{6}$ The authors of both of these studies recommended that healthcare professionals in Oman be aware of, and respect, their patients' coping strategies and that these women should be provided with more support to reduce the psychological symptoms, distress and 
dilemmas related to a breast cancer diagnosis., ${ }^{5,6}$ Indeed, care for cancer patients should be provided as a "continuum", including risk assessment, primary and secondary prevention, early detection, diagnosis, treatment, follow-up and end-of-life care. ${ }^{17}$

Bearing in mind the QoL benefits of psychological interventions in helping women cope with a breast cancer diagnosis, several measures should be considered to integrate psychological interventions into the healthcare system in Oman. A psychological intervention service to support patients and their caregivers immediately following diagnosis and during treatment should be established in the oncology units of tertiary care referral hospitals. The oncology teams in these hospitals also need to be made aware of the importance of the psychological aspects of a cancer diagnosis, so that they can anticipate and recognise patients suffering from psychological symptoms, allowing them to make timely referrals to counsellors. Supportive-expressive groups should be initiated in the main government hospitals of Oman, such as the National Oncology Center at the Royal Hospital and the Sultan Qaboos University Hospital in Muscat, Oman. Nurses as well as other healthcare professionals can be trained by mental healthcare providers to conduct psychological interventions for Omani women diagnosed with breast cancer. Psychological services can also be introduced at the community level through local health centres, providing mental health services and forming support groups for patients who have been discharged.

Policy-makers, in cooperation with health psychologists, should initiate public screening and awareness programmes to educate Omani women on the benefits of the early detection of breast cancer and post-diagnosis psychological support services. Although the Omani government has initiated campaigns on breast cancer awareness in the past, these campaigns alone were not effective. ${ }^{6}$ Nongovernmental organisations, such as the Oman Cancer Association, could take steps to improve public awareness of the benefits of psychological interventions. There is also a need for collaboration with the media, both print and electronic, such as local newspapers and magazines as well as radio and television stations, in order to spread cancer awareness and support for breast cancer patients and the need for psychological support services. Furthermore, an Arabic-language interactive website for patient education and promotion of psychological interventional therapy for cancer patients is necessary.

There is a definite need and role for clinical psychologists in the management of cancer patients from the outset, at the screening and genetic testing stages. However, the successful implementation of psychological support services and active interventions for Omani women with breast cancer can only be brought about following the development of the necessary human resources, training, commitment, advocacy and infrastructure. The initiation of these services could be taken on by appropriate authorities at the Ministry of Health in Oman, with support from the Sultan Qaboos University Hospital as well as the National Oncology Center. These efforts could help decrease the negative attitudes and shame associated with a breast cancer diagnosis, in the hope that Oman will be able to transform itself into a stigma-free nation with regards to the fight against breast cancer.

\section{References}

1. Jemal A, Bray F, Center MM, Ferlay J, Ward E, Forman D. Global cancer statistics. CA Cancer J Clin 2011; 61:69-90. doi: 10.3322/caac.20107.

2. Mehdi I, Monem EA, Al Bahrani BJ, Al Kharusi S, Nada AM, $\mathrm{Al}$ Lawati J, et al. Age at diagnosis of female breast cancer in Oman: Issues and implications. South Asian J Cancer 2014; 3:101-6. doi: 10.4103/2278-330X.130442.

3. Al-Moundhri M, Al-Bahrani B, Pervez I, Ganguly SS, Nirmala V, Al-Madhani A, et al. The outcome of treatment of breast cancer in a developing country: Oman. Breast 2004; 13:139-45. doi: 10.1016/j.breast.2003.10.001.

4. Badger TA, Braden CJ, Mishel MH, Longman A. Depression burden, psychological adjustment, and quality of life in women with breast cancer: Patterns over time. Res Nurs Health 2004; 27:19-28. doi: 10.1002/nur.20002.

5. Al-Azri M, Al-Awisi H, Al-Rasbi S, El-Shafie K, Al-Hinai M, Al-Habsi $\mathrm{H}$, et al. Psychosocial impact of breast cancer diagnosis among Omani women. Oman Med J 2014; 29:437-44. doi: 10.5001/omj.2014.115.

6. Al-Azri $\mathrm{MH}$, Al-Awisi $\mathrm{H}$, Al-Rasbi $\mathrm{S}$, Al-Moundhri $\mathrm{M}$. Coping with a diagnosis of breast cancer amongst Omani women. J Health Psychol 2014; 19:836-46. doi: 10.1177/135 9105313479813.

7. Else-Quest NM, LoConte NK, Schiller JH, Hyde JS. Perceived stigma, self-blame, and adjustment among lung, breast and prostate cancer patients. Psychol Health 2009; 24:949-64. doi: 10.1080/08870440802074664.

8. Abu-Helalah M, Al-Hanaqta M, Alshraideh H, Abdulbaqi N, Hijazeen J. Quality of life and psychological well-being of breast cancer survivors in Jordan. Asian Pac J Cancer Prev 2014; 15:5927-36. doi: 10.7314/APJCP.2014.15.14.5927.

9. Hodges LJ, Walker J, Kleiboer AM, Ramirez AJ, Richardson A, Velikova $\mathrm{G}$ et al. What is a psychological intervention? A metareview and practical proposal. Psychooncology 2011; 20:470-8. doi: 10.1002/pon.1780.

10. Casellas-Grau A, Font A, Vives J. Positive psychology interventions in breast cancer: A systematic review. Psychooncology 2014; 23:9-19. doi: 10.1002/pon.3353.

11. Faller H, Schuler M, Richard M, Heckl U, Weis J, Küffner R. Effects of psycho-oncologic interventions on emotional distress and quality of life in adult patients with cancer: Systematic review and meta-analysis. J Clin Oncol 2013; 31:782-93. doi: 10.1200/JCO.2011.40.8922. 
12. Hunter MS, Coventry S, Hamed H, Fentiman I, Grunfeld EA. Evaluation of a group cognitive behavioural intervention for women suffering from menopausal symptoms following breast cancer treatment. Psychooncology 2009; 18:560-3. doi: $10.1002 /$ pon.1414.

13. Andersen BL. Biobehavioral outcomes following psychological interventions for cancer patients. J Consult Clin Psychol 2002; 70:590-610. doi: 10.1037/0022-006X.70.3.590.

14. Jassim GA, Whitford DL, Hickey A, Carter B. Psychological interventions for women with non-metastatic breast cancer. Cochrane Database Syst Rev 2015; 28:CD008729. doi: 10.1002/ 14651858.CD008729.pub2.
15. Spiegel D, Bloom JR, Yalom I. Group support for patients with metastatic cancer: A randomized outcome study. Arch Gen Psychiatry 1981; 38:527-33. doi: 10.1001/archpsyc.1980.0178 0300039004.

16. Classen C, Butler LD, Koopman C, Miller E, DiMiceli S, Giese-Davis J, et al. Supportive-expressive group therapy and distress in patients with metastatic breast cancer: A randomized clinical intervention trial. Arch Gen Psychiatry 2001; 58:494-501. doi: 10.1001/archpsyc.58.5.494.

17. Al-Moundhri M. The need for holistic cancer care framework: Breast cancer care as an example. Oman Med J 2013; 28:300-1. doi: 10.5001/omj.2013.90. 